\title{
Development of a versatile source apportionment analysis based on posi- tive matrix factorization: a case study of the seasonal variation of organic aerosol sources in Estonia
}

Athanasia Vlachou et al.

Correspondence to: André S. H. Prévôt (andre.prevot@psi.ch) and Imad El Haddad (imad.el-haddad@psi.ch)

The copyright of individual parts of the supplement might differ from the CC BY 4.0 License. 
Table S1. Dates per site.

\begin{tabular}{|c|c|c|c|c|c|}
\hline $\mathrm{KJ}$ & Tallinn & Tartu & $\mathrm{KJ}$ & Tallinn & Tartu \\
\hline \multicolumn{3}{|c|}{2013} & \multicolumn{3}{|c|}{2014} \\
\hline \multirow[t]{2}{*}{31.08 .2013} & & & & & 03.01 .2014 \\
\hline & 05.09 .2013 & 05.09 .2013 & & 05.01 .2014 & \\
\hline \multirow[t]{6}{*}{ 08.09.2013 } & 08.09 .2013 & & 06.01 .2014 & & \\
\hline & & 09.09 .2013 & & & 07.01 .2014 \\
\hline & 12.09 .2013 & & & 11.01.2014 & \\
\hline & 13.09 .2013 & & & 19.01 .2014 & 19.01 .2014 \\
\hline & 16.09 .2013 & & 22.01 .2014 & & \\
\hline & & 17.09 .2013 & & 26.01 .2014 & \\
\hline \multirow[t]{4}{*}{ 20.09.2013 } & 20.09.2013 & & & 02.02 .2014 & \\
\hline & 22.09 .2013 & & & & 27.01.2014 \\
\hline & & 29.09.2013 & 03.02 .2014 & 03.02 .2014 & \\
\hline & 30.09 .2013 & & & 06.02 .2014 & \\
\hline \multirow[t]{4}{*}{02.10 .2013} & & & & 07.02 .2014 & \\
\hline & 07.10 .2013 & & & & 08.02 .2014 \\
\hline & 10.10 .2013 & & & 09.02 .2014 & \\
\hline & & 11.10.2013 & 11.02 .2014 & & \\
\hline 14.10 .2013 & 14.10 .2013 & & 15.02 .2014 & & \\
\hline \multirow[t]{3}{*}{18.10 .2013} & & & & 16.02 .2014 & \\
\hline & 21.10 .2013 & & & & 20.02 .2014 \\
\hline & & 23.10 .2013 & & 23.02.2014 & \\
\hline \multirow[t]{3}{*}{26.10 .2013} & & & & & 24.02 .2014 \\
\hline & 27.10 .2013 & 27.10.2013 & 27.02 .2014 & & \\
\hline & 04.11 .2013 & & & 28.02.2014 & \\
\hline \multirow[t]{4}{*}{07.11 .2013} & & & & 01.03 .2014 & \\
\hline & & 08.11 .2013 & & 02.03 .2014 & \\
\hline & 10.11.2013 & & & & 04.03 .2014 \\
\hline & 17.11 .2013 & & & & 08.03.2014 \\
\hline \multirow[t]{2}{*}{ 19.11.2013 } & & & & 10.03 .2014 & \\
\hline & & 20.11 .2013 & 11.03 .2014 & & 16023014 \\
\hline \multirow{2}{*}{ 23.11.2013 } & 24.11.2013 & & & 17.03 .2014 & 16.03 .2014 \\
\hline & & 28.11.2013 & & & 20.03 .2014 \\
\hline \multirow[t]{2}{*}{01.12 .2013} & 01.12 .2013 & & & 22.03 .2014 & \\
\hline & 08.12 .2013 & & 23.03 .2014 & 27.03 .2014 & \\
\hline \multirow[t]{2}{*}{13.12 .2013} & & & & & 28.03 .2014 \\
\hline & 16.12 .2013 & 14.12 .2013 & 31.03 .2014 & 30.03 .2014 & \\
\hline \multirow[t]{3}{*}{17.12 .2013} & & & 04.04 .2014 & & \\
\hline & 23.12.2013 & & & 06.04 .2014 & \\
\hline & 26.12 .2013 & 26.12 .2013 & & & 09.04 .2014 \\
\hline \multirow[t]{5}{*}{ 29.12.2013 } & & & & 13.04 .2014 & \\
\hline & 30.12 .2013 & & 16.04 .2014 & 20.04 .2014 & \\
\hline & & & & & 21.04 .2014 \\
\hline & & & & 25.04 .2014 & 25.04 .2014 \\
\hline & & & 28.04.2014 & & \\
\hline
\end{tabular}




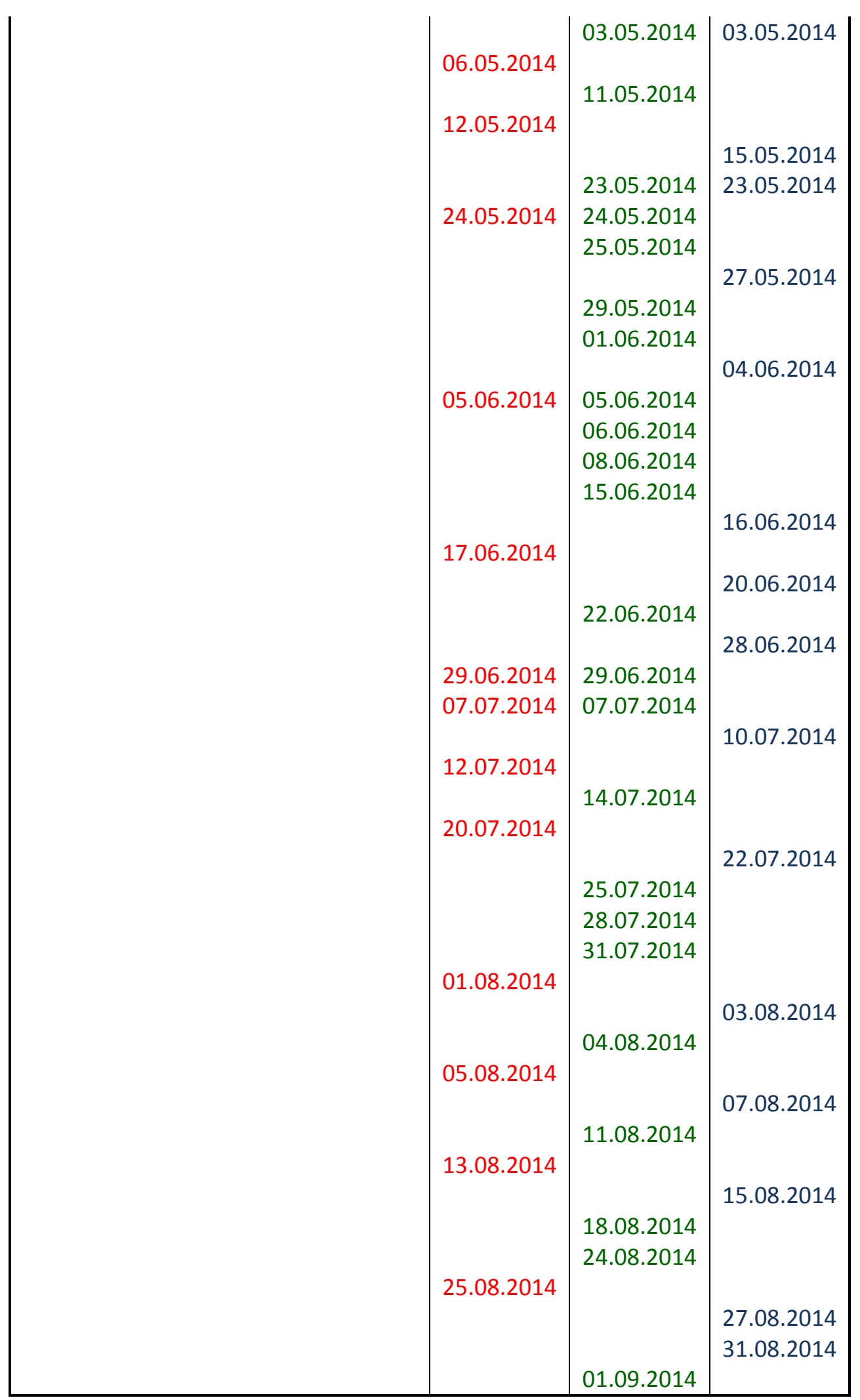




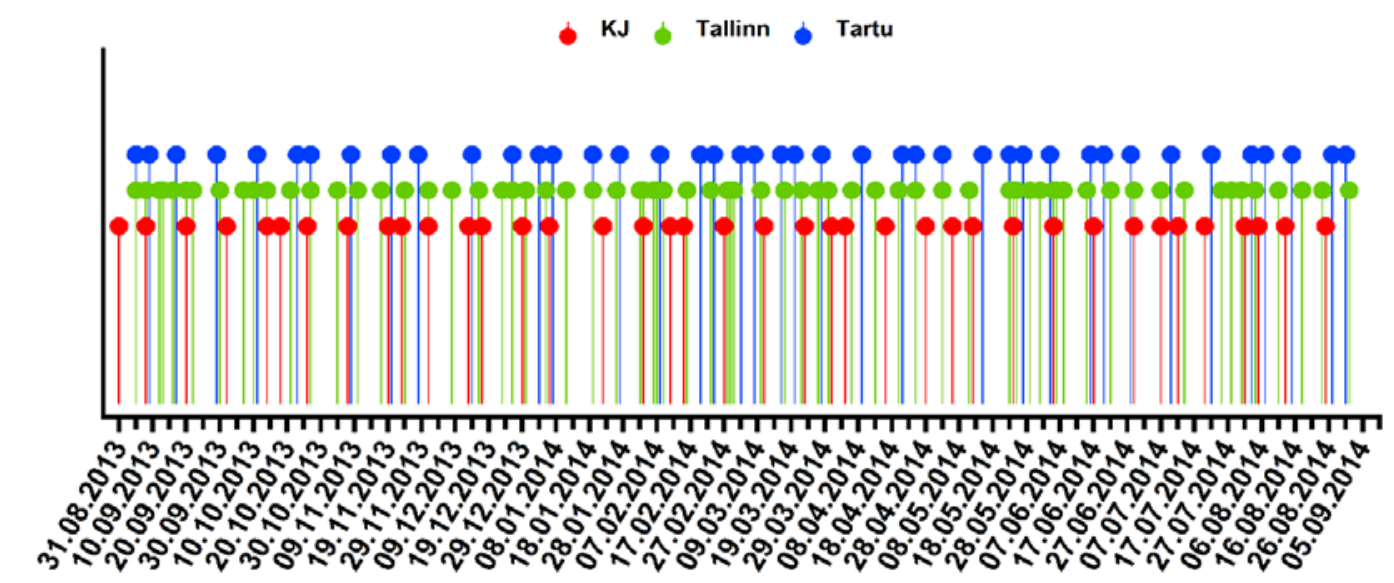

Figure S1. Dates per site. KJ represented in red, Tallinn in green and Tartu in blue.

Table S2. Number of samples per season per site.

\begin{tabular}{|c|c|c|c|}
\hline & \multicolumn{3}{|c|}{ Number of samples per season } \\
\hline Seasons & KJ & Tallinn & Tartu \\
\hline Summer & 11 & 16 & 11 \\
\hline Autumn & 9 & 18 & 10 \\
\hline Winter & 10 & 18 & 9 \\
\hline Spring & 9 & 17 & 12 \\
\hline
\end{tabular}

Table S3. Percentages of true positive and true negative values (accuracy) per factor and the probabilities of false positive and false negative values (probability) for the "ts" method.

\begin{tabular}{|c|c|c|c|c|}
\hline & \multicolumn{2}{|c|}{ Accuracy } & \multicolumn{2}{|c|}{ Probability } \\
\hline $\begin{array}{l}\text { Time } \\
\text { Series }\end{array}$ & $\begin{array}{l}\text { True } \\
\text { Positive }\end{array}$ & $\begin{array}{l}\text { True } \\
\text { Negative }\end{array}$ & $\begin{array}{l}\text { False } \\
\text { Positive }\end{array}$ & $\begin{array}{l}\text { False } \\
\text { Negative }\end{array}$ \\
\hline BBOA & $98 \%$ & $54 \%$ & $20 \%$ & $8 \%$ \\
\hline PBOA & $91 \%$ & $100 \%$ & $0 \%$ & $53 \%$ \\
\hline WOOA & $99 \%$ & $17 \%$ & $3 \%$ & $50 \%$ \\
\hline SOOA & $100 \%$ & $0 \%$ & $16 \%$ & $0 \%$ \\
\hline
\end{tabular}

Table S4. Percentages of true positive and true negative values (accuracy) per factor and the probabilities of false positive and false negative values (probability) for the "pr" method.

\begin{tabular}{|c|c|c|c|c|}
\hline & \multicolumn{2}{|c|}{ Accuracy } & \multicolumn{2}{|c|}{ Probability } \\
\hline Profiles & $\begin{array}{l}\text { True } \\
\text { Positive }\end{array}$ & $\begin{array}{l}\text { True } \\
\text { Negative }\end{array}$ & $\begin{array}{l}\text { False } \\
\text { Positive }\end{array}$ & $\begin{array}{l}\text { False } \\
\text { Negative }\end{array}$ \\
\hline BBOA & $87 \%$ & $68 \%$ & $20 \%$ & $21 \%$ \\
\hline PBOA & $91 \%$ & $100 \%$ & $0 \%$ & $56 \%$ \\
\hline WOOA & $92 \%$ & $0 \%$ & $1 \%$ & $100 \%$ \\
\hline SOOA & $96 \%$ & $17 \%$ & $11 \%$ & $67 \%$ \\
\hline
\end{tabular}



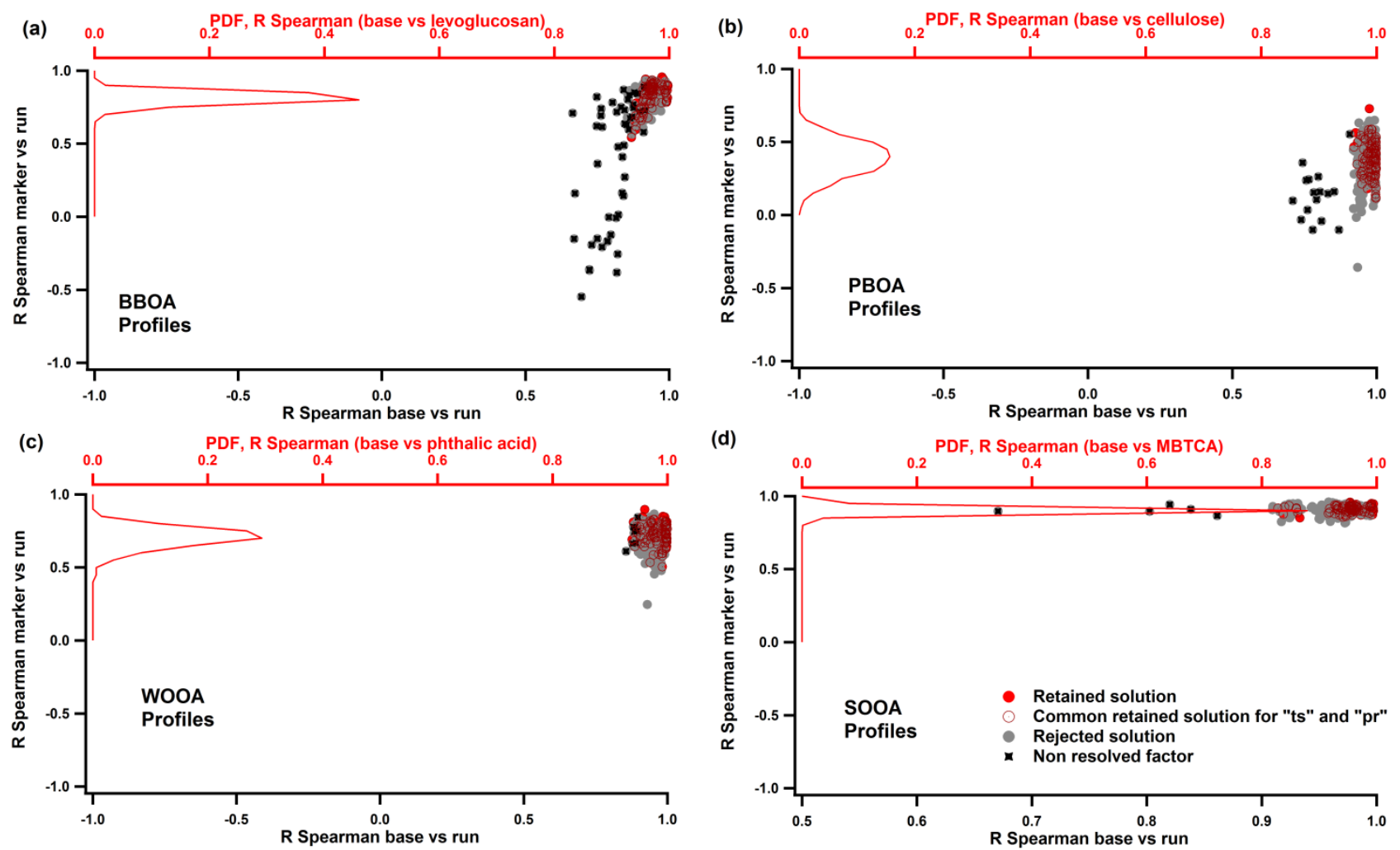

Figure S2. Solution space per factor defined by investigation of the correlation $(R \mathrm{~s})$ between base case factor profiles and bootstrap run (bottom $\mathrm{x}$-axis) and external marker and bootstrap run (y-axis): BBOA with levoglucosan (a), PBOA with cellulose (b), WOOA with phthalic acid (c) and SOOA with MBTCA (d). The retained solutions are indicated in red and the rejected ones in grey. The points in black represent the runs where the specific factor was not resolved at all. Each PDF (top x-axis) includes the range of $R$ s of the correlation between the time series of each base case factor with its respective marker. 

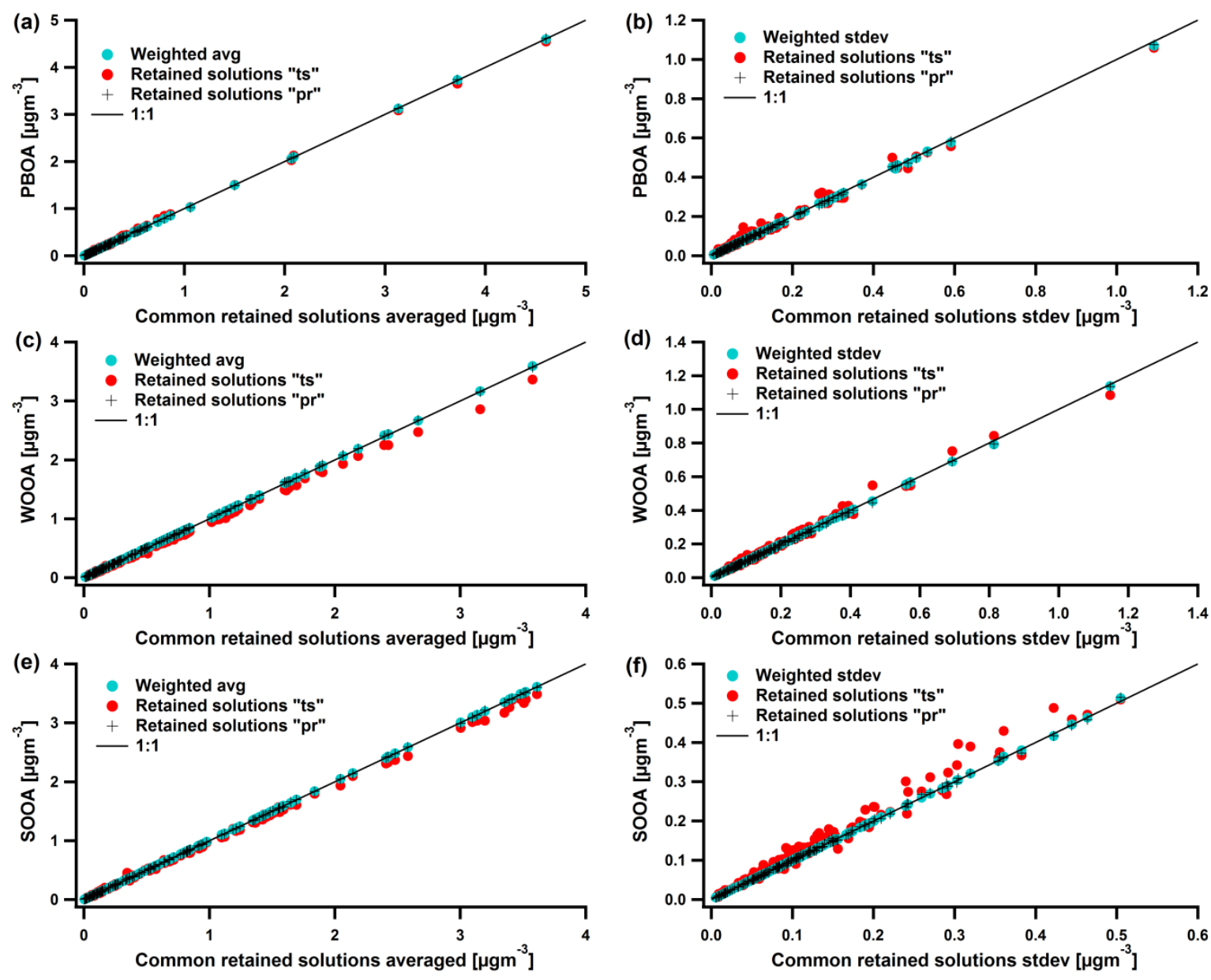

Fig. S3. Scatter plots between factor OA time series averaged (avg) over the common solutions coming from the time series ("ts") and profile ("pr") sorting method plotted in the x-axis, and plotted in the $y$-axis the factor OA time series averaged over the solutions coming from the "ts" method in red, from the "pr" in black cross and from the weighted average based on the marker, in blue: PBOA and cellulose (a), WOOA and phthalic acid (c) and SOOA and MBTCA (e). The respective scatter plot for the standard deviation (stdev) is shown in (b), (d) and (f). 


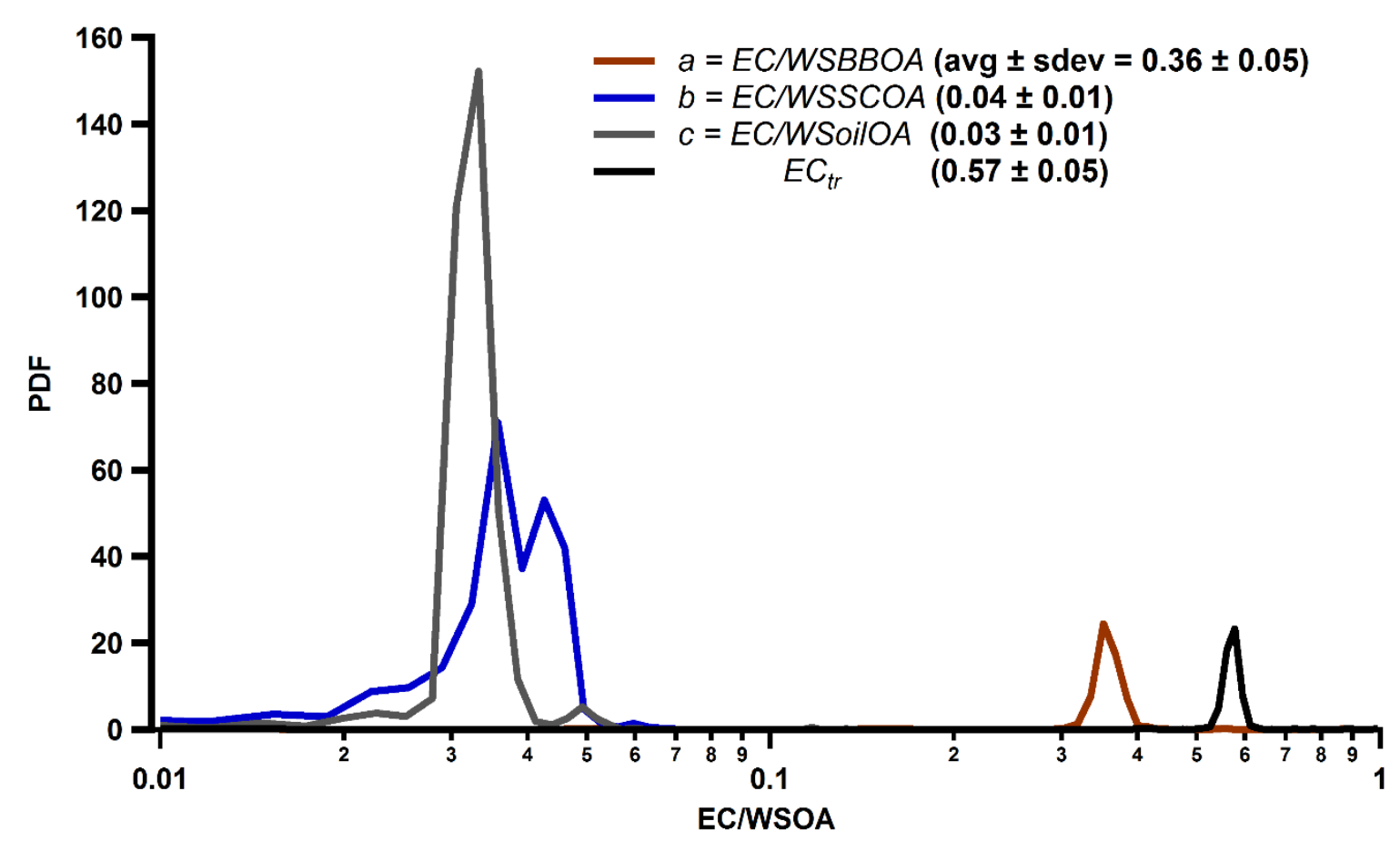

Figure S4. Probability density functions for the EC:WSOA ratios ( $a$ for WSBBOA, $b$ for WSSCOA and $c$ for WSoilOA) characteristic of the emissions from the same sources obtained by the 1000 PMF runs.

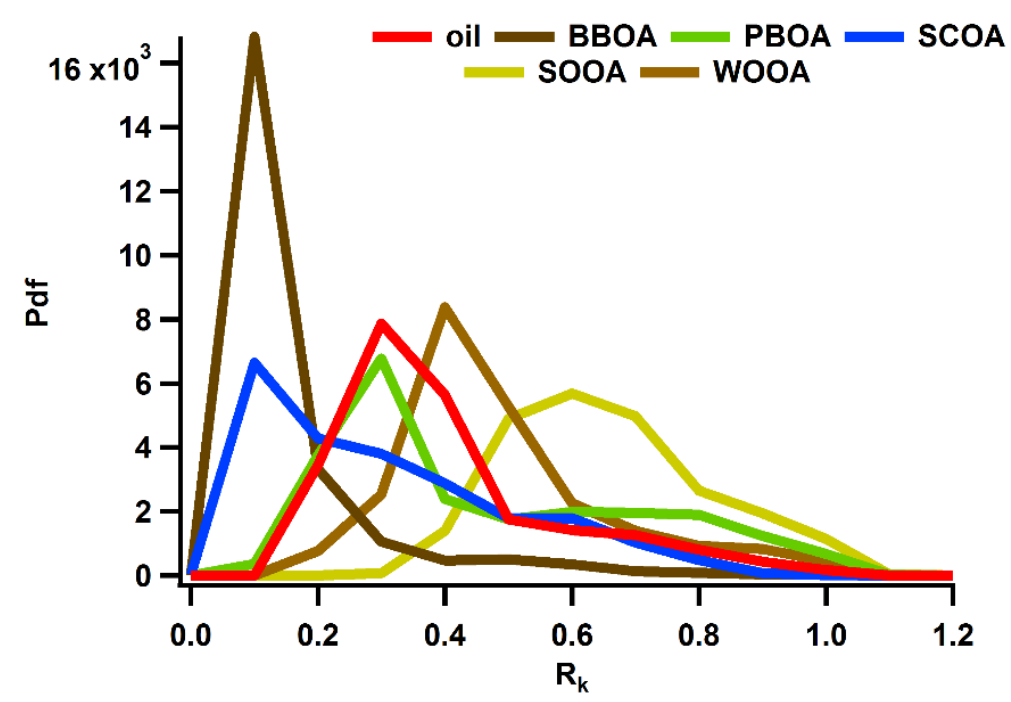

Figure S5. Probability density functions of the recoveries of each factor: oil in red, BBOA in dark brown, PBOA in green, SCOA in blue, SOOA in yellow and WOOA in light brown. 


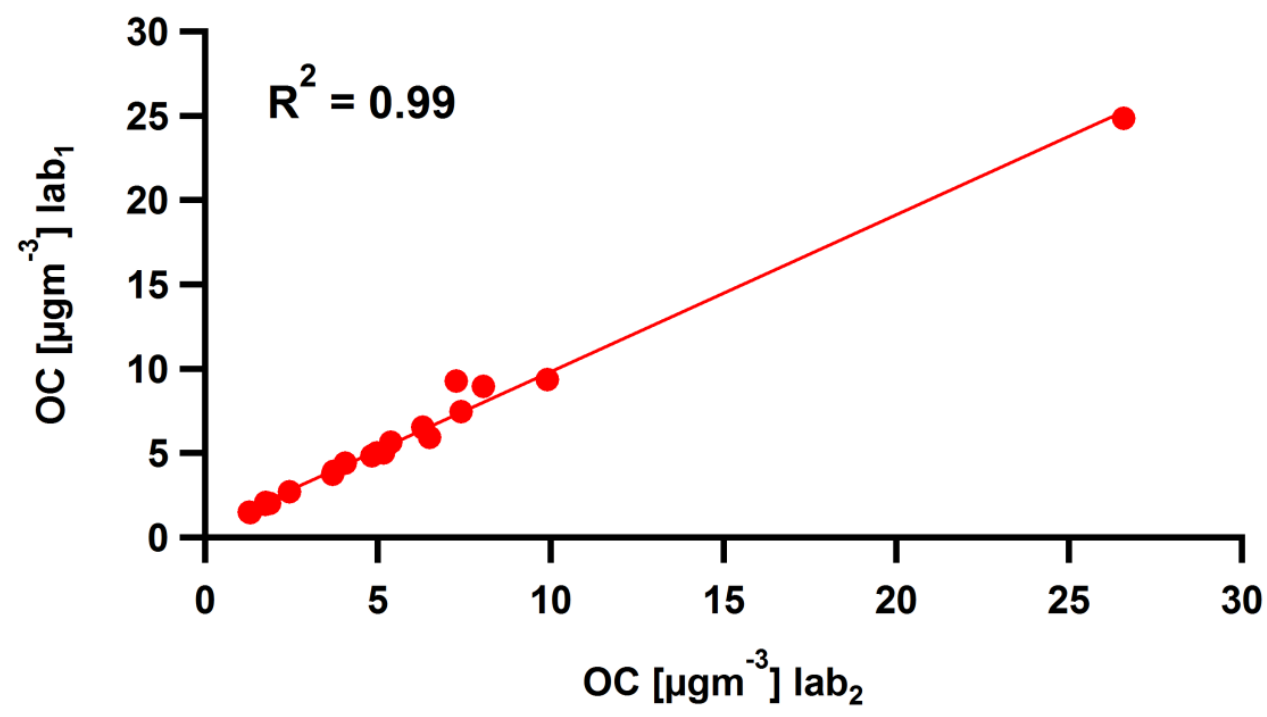

Figure S6. Correlation between OC measured in Bern (lab ${ }_{1}$ : MICADAS lab, University of Bern) and OC measured in Grenoble (lab2: Université Grenoble Alpes).

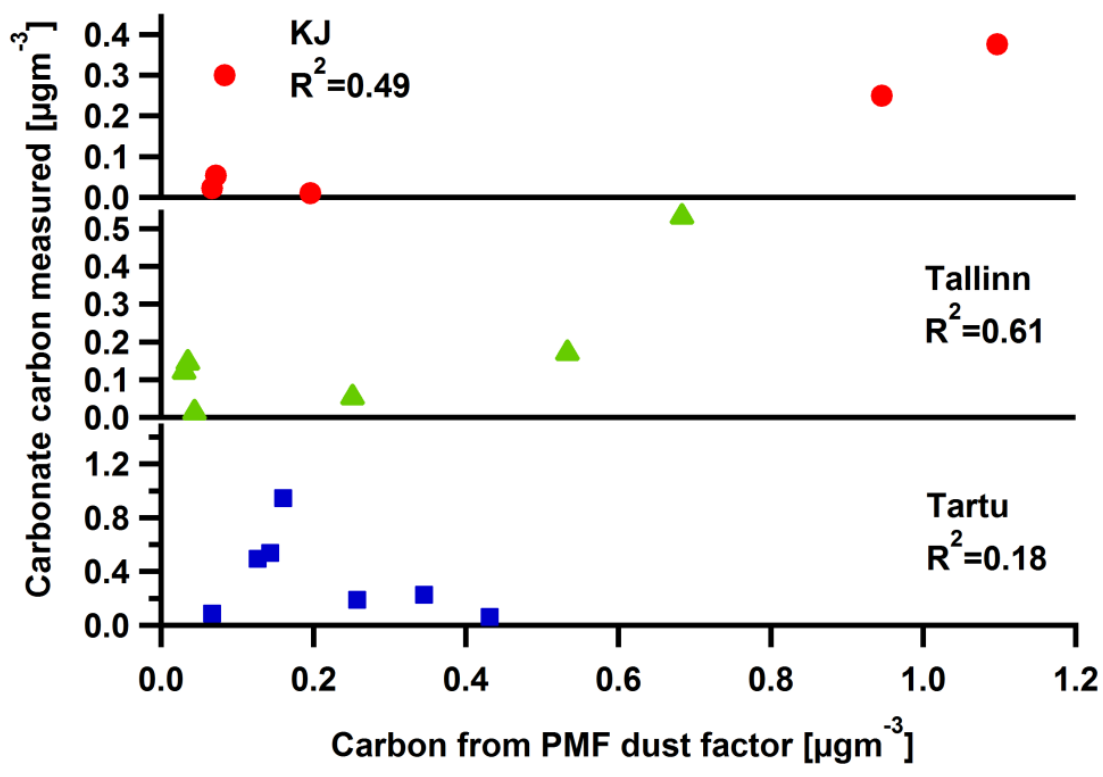

5 Figure S7. Correlations between carbonate carbon measured and modelled for each site.

\section{Carbonate carbon calculation}

In order to estimate the contribution of the carbonate carbon $\left(\mathrm{C}_{-} \mathrm{CO}_{3}\right)$ in the inorganic dust factor, we calculated the fraction of $\mathrm{C}_{-} \mathrm{CO}_{3}\left(f_{\mathrm{C}_{-} \mathrm{CO}}\right)$ based on Eq. S1:

$10 \quad f_{\mathrm{C}_{-} \mathrm{CO}, i}=\frac{f_{\text {Dust_PMF }}}{\sum_{i=1}^{6} W_{S O C_{i}} /\left(\frac{O M}{O C}\right) i+f_{\text {Dust_PMF }} /\left(\frac{O M}{O C}\right) \text { Dust }}$

where $i$ indicates the factor (6 OA factors) and $f_{D u s t_{-} P M F}$ the fraction of the PMF identified, inorganic dust factor: 
$f_{\text {Dust_PMF }}=\frac{\text { Dust_PMF*RIE } \mathrm{CO}_{3}}{\sum_{i=1}^{6} \text { OAi } * \text { RIEorg }+ \text { Dust_PMF*RIE } \mathrm{CO}_{3}}$

with OAi representing the organic aerosol factor concentrations, Dust_PMF the concentration of the inorganic dust factor as obtained from PMF, RIEorg and $\mathrm{RIE}_{\mathrm{CO}_{3}}$ the relative ionisation efficiency of the organics (1.4, Canagaratna et al., 2007) and carbonate (1.16, Bozzetti et al., 2017) respectively.

Finally, we multiplied all water soluble OC (WSOC) factors by the ratio 1 / ( $\left.1-f_{\mathrm{C}_{-} \text {соз,i }}\right)$ to rescale the sum of the 6 WSOC factor concentrations to the externally measured WSOC, given that the dust factor is inorganic.

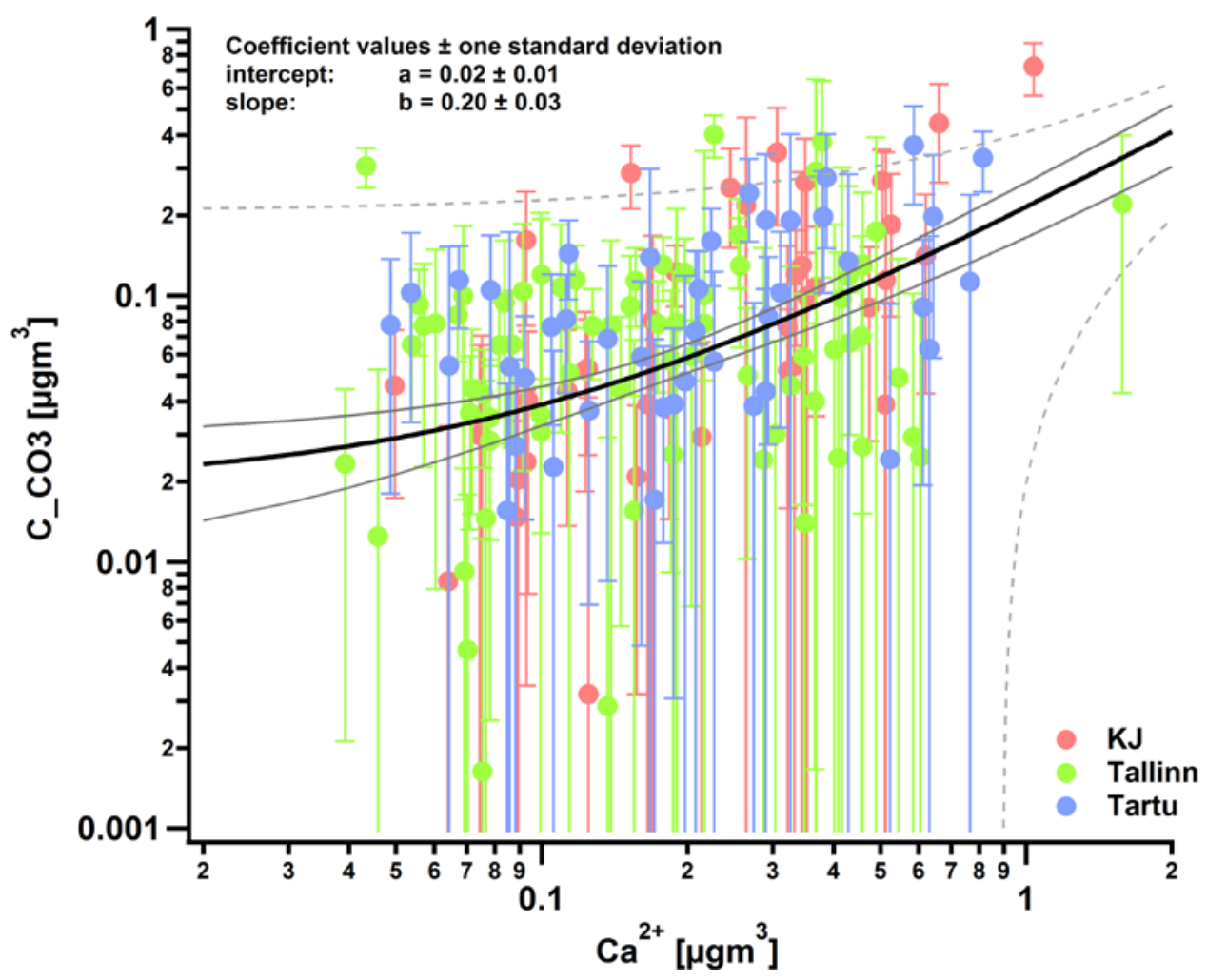

10 Figure S8. Scatter plot in logarithmic scale between calculated carbonate carbon $\left(\mathrm{C}_{-} \mathrm{CO}_{3}\right)$ and $\mathrm{Ca}^{2+}$. The black solid line indicates the linear regression, the grey solid lines the confidence bands and the grey dashed lines the predicted bands. Red represents KJ, green Tallinn and blue Tartu. 


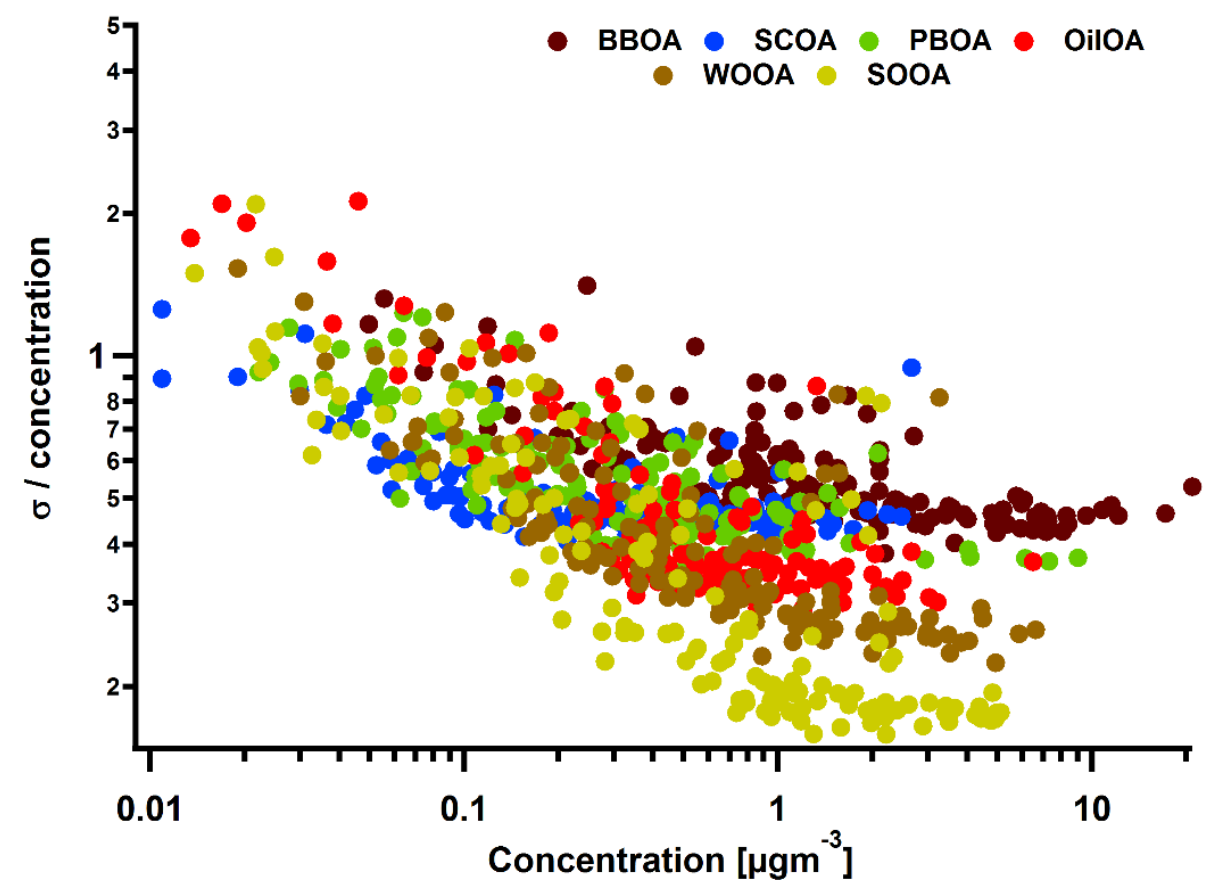

Figure S9. Concentration uncertainties $\sigma$ for each PMF factor as a function of factor concentration.

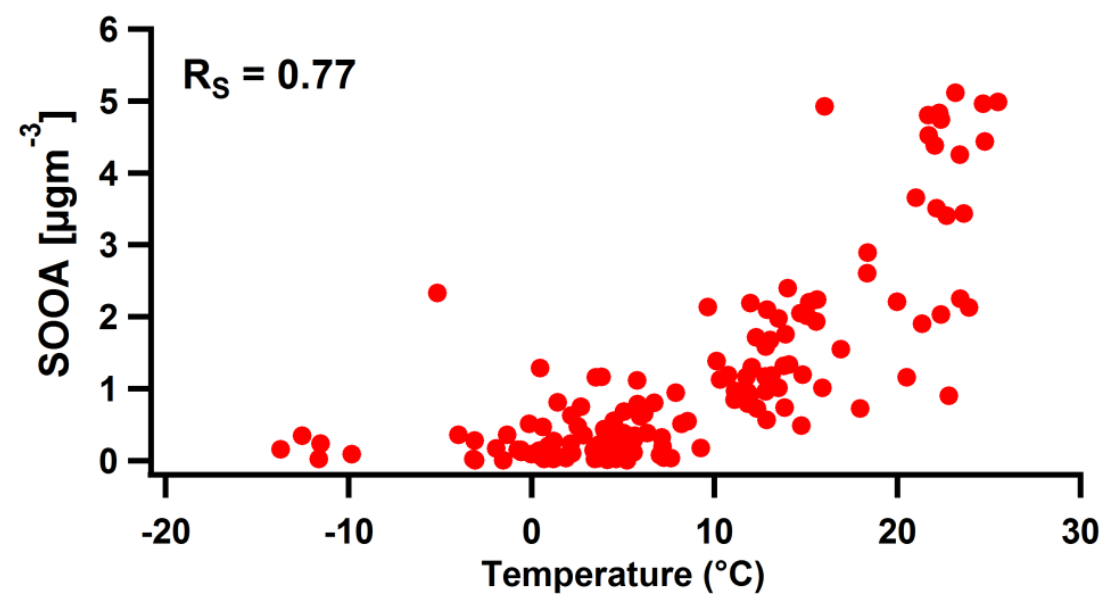

Figure S10. Exponential dependency of SOOA on temperature. The scatter plot includes all sites. 
Table S5. OA concentrations per factor per season, with uncertainties.

\begin{tabular}{|c|c|c|c|c|c|c|c|c|c|c|c|c|}
\hline Factor & \multicolumn{3}{|c|}{$\begin{array}{c}\text { Autumn } \\
\left(\mu \mathrm{gm}^{-3}\right)\end{array}$} & \multicolumn{3}{c|}{$\begin{array}{c}\text { Winter } \\
\left(\mu \mathrm{gm}^{-3}\right)\end{array}$} & \multicolumn{3}{c|}{$\begin{array}{c}\text { Spring } \\
\left(\mu \mathrm{gm}^{-3}\right)\end{array}$} & \multicolumn{3}{c|}{$\begin{array}{c}\text { Summer } \\
\left(\mu \mathrm{gm}^{-3}\right)\end{array}$} \\
\hline & KJ & Tallinn & Tartu & KJ & Tallinn & Tartu & KJ & Tallinn & Tartu & KJ & Tallinn & Tartu \\
BBOA & $1.1 \pm 0.7$ & $1.2 \pm 0.9$ & $3.8 \pm 1.9$ & $1.3 \pm 0.8$ & $3.7 \pm 2.7$ & $8.4 \pm 3.9$ & $0.3 \pm 0.3$ & $2.3 \pm 1.6$ & $4.0 \pm 3.5$ & $1.2 \pm 1.0$ & $0.9 \pm 0.6$ & $1.6 \pm 0.8$ \\
SCOA & $0.2 \pm 0.1$ & $0.5 \pm 0.3$ & $0.3 \pm 0.2$ & $0.3 \pm 0.2$ & $0.7 \pm 0.4$ & $0.2 \pm 0.1$ & $0.3 \pm 0.2$ & $0.6 \pm 0.4$ & $0.4 \pm 0.3$ & $0.8 \pm 0.5$ & $0.5 \pm 0.3$ & $0.4 \pm 0.2$ \\
PBOA & $0.1 \pm 0.1$ & $0.3 \pm 0.2$ & $0.7 \pm 0.3$ & $0.1 \pm 0.1$ & $0.3 \pm 0.2$ & $0.9 \pm 0.5$ & $0.2 \pm 0.2$ & $1.2 \pm 0.8$ & $2.1 \pm 1.3$ & $0.4 \pm 0.2$ & $0.4 \pm 0.2$ & $0.5 \pm 0.2$ \\
Oil OA & $0.7 \pm 0.3$ & $0.4 \pm 0.3$ & $0.3 \pm 0.2$ & $0.4 \pm 0.2$ & $0.6 \pm 0.2$ & $0.2 \pm 0.1$ & $1.4 \pm 0.9$ & $0.8 \pm 0.3$ & $0.7 \pm 0.4$ & $1.4 \pm 0.5$ & $1.0 \pm 0.4$ & $0.9 \pm 0.3$ \\
WOOA & $1.6 \pm 0.5$ & $0.6 \pm 0.4$ & $1.3 \pm 0.5$ & $1.4 \pm 0.5$ & $2.2 \pm 0.8$ & $1.5 \pm 0.5$ & $0.3 \pm 0.1$ & $1.0 \pm 0.4$ & $0.6 \pm 0.3$ & $0.8 \pm 0.5$ & $0.5 \pm 0.2$ & $0.2 \pm 0.1$ \\
SOOA & $0.3 \pm 0.1$ & $1.1 \pm 0.4$ & $0.9 \pm 0.2$ & $0.1 \pm 0.1$ & $0.3 \pm 0.2$ & $0.2 \pm 0.2$ & $0.7 \pm 0.2$ & $1.4 \pm 0.4$ & $0.9 \pm 0.3$ & $1.8 \pm 0.7$ & $2.8 \pm 0.6$ & $2.1 \pm 0.4$ \\
\hline
\end{tabular}

Table S6. Relative contributions per factor per season to the OA, with uncertainties.

5

\begin{tabular}{|c|c|c|c|c|c|c|c|c|c|c|c|c|}
\hline \multirow[t]{2}{*}{ Factor } & \multicolumn{3}{|c|}{$\begin{array}{c}\text { Autumn } \\
\text { (\%) }\end{array}$} & \multicolumn{3}{|c|}{$\begin{array}{c}\text { Winter } \\
(\%)\end{array}$} & \multicolumn{3}{|c|}{$\begin{array}{c}\text { Spring } \\
(\%)\end{array}$} & \multicolumn{3}{|c|}{$\begin{array}{c}\text { Summer } \\
\text { (\%) }\end{array}$} \\
\hline & KJ & Tallinn & Tartu & KJ & Tallinn & Tartu & KJ & Tallinn & Tartu & KJ & Tallinn & Tartu \\
\hline BBOA & $24 \pm 18$ & $27 \pm 13$ & $53 \pm 14$ & $30 \pm 19$ & $39 \pm 16$ & $73 \pm 21$ & $14 \pm 11$ & $30 \pm 14$ & $47 \pm 18$ & $18 \pm 12$ & $17 \pm 12$ & $30 \pm 16$ \\
\hline SCOA & $4 \pm 2$ & $16 \pm 5$ & $4 \pm 1$ & $13 \pm 5$ & $18 \pm 6$ & $2 \pm 1$ & $16 \pm 5$ & $12 \pm 4$ & $5 \pm 2$ & $13 \pm 3$ & $10 \pm 3$ & $7 \pm 2$ \\
\hline PBOA & $3 \pm 2$ & $7 \pm 3$ & $9 \pm 5$ & $3 \pm 2$ & $3 \pm 2$ & $9 \pm 6$ & $7 \pm 4$ & $11 \pm 5$ & $21 \pm 8$ & $6 \pm 3$ & $7 \pm 3$ & $9 \pm 4$ \\
\hline Oil OA & $16 \pm 5$ & $13 \pm 4$ & $4 \pm 2$ & $15 \pm 6$ & $11 \pm 5$ & $1 \pm 1$ & $36 \pm 14$ & $14 \pm 5$ & $8 \pm 3$ & $26 \pm 7$ & $16 \pm 5$ & $15 \pm 4$ \\
\hline WOOA & $39 \pm 13$ & $13 \pm 5$ & $16 \pm 6$ & $36 \pm 14$ & $25 \pm 9$ & $13 \pm 5$ & $13 \pm 6$ & $15 \pm 7$ & $9 \pm 5$ & $11 \pm 4$ & $9 \pm 4$ & $4 \pm 3$ \\
\hline SOOA & $14 \pm 5$ & $24 \pm 5$ & $13 \pm 3$ & $4 \pm 2$ & $3 \pm 2$ & $2 \pm 1$ & $14 \pm 5$ & $18 \pm 5$ & $11 \pm 3$ & $26 \pm 5$ & $41 \pm 7$ & $35 \pm 7$ \\
\hline
\end{tabular}

\section{References}

Bozzetti, C., El Haddad, I., Salameh, D., Daellenbach, K. R., Fermo, P., Gonzalez, R., Minguillón, M. C., Iinuma, Y., Poulain, L., Elser, M., Müller, E., Slowik, J. G., Jaffrezo, J.-L., 10 Baltensperger, U., Marchand, N., Prévôt, A. S. H.: Organic aerosol source apportionment by offline-AMS over a full year in Marseille, Atmos. Chem. Phys., 17, 8247-8268, doi:10.5194/acp-17-8247-2017, 2017b. 
Canagaratna, M. R., Jayne, J. T., Jimenez, J. L., Allan, J. D., Alfarra, M. R., Zhang, Q., Onasch, T. B., Drewnick, F., Coe, H., Middlebrook, A., Delia, A., Williams, L. R., Trimborn, A. M., Northway, M. J., DeCarlo, P. F., Kolb, C. E., Davidovits, P. and Worsnop, D. R.: Chemical and microphysical characterization of ambient aerosols with the Aerodyne aerosol mass 5 spectrometer, Mass Spectrom. Rev., 26, 185-222, doi:10.1002/mas.20115, 2007. 